\title{
A vacuum nano-casting route to magnetite cores/ mesoporous silica shell composites
}

\section{M. Guo and J. L. Shi}

Hollow mesoporous silica spheres with magnetite cores (HMSMC) have been fabricated by Vacuum Nano-casting Route. The amount of magnetite cores and saturation magnetization value can be easily adjusted by changing the concentration of iron nitrate solution used in the synthesis procedure. Furthermore, the as-prepared HMSMCs still maintain narrow mesopore distribution, high surface area and large pore volume after the hollow cores of hollow mesoporous silica spheres were filled with magnetite particles. Specially, when the saturation magnetization value of as-prepared HMSMCs reaches $22.0 \mathrm{emu} / \mathrm{g}$, the surface area and pore volume of corresponding HMSMCs are $149 \mathrm{~m}^{2} / \mathrm{g}$ and $0.19 \mathrm{~cm}^{3} / \mathrm{g}$, respectively, and the pore size is $2.30 \mathrm{~nm}$. The corresponding samples are characterized by $\mathrm{X}$-ray diffraction, $\mathrm{N}_{2}$ sorption isotherms, transmission electron microscopy and vibrating-sample magnetometer.

Keywords: Hollow mesoporous silica spheres; Magnetite cores; Vacuum nano-casting

Citation: L. M. Guo and J. L. Shi, "A vacuum nano-casting route to magnetite cores/mesoporous silica shell composites”, Nano-Micro Lett. 1, 27-29 (2009). doi: 10.5101/nml.v1i1.p27-29

A number of literatures have described the formation of hollow mesoporous spheres in the past few years [1-8], and it is generally accepted that hollow spheres with mesoporous shells will exhibit more advantages in mass diffusion and transportation compared with conventional hollow spheres of solid shells [4,8]. On the other hand, magnetic particles embedded in mesoporous materials have been intensively pursued for its emergent applications in biomedicine and efficient separable catalysis [9-14]. Due to their large pore size, high surface area, spherical morphology and magnetism, mesoporous spheres incorporated with magnetic particles have attracted great attention [15-19]. There have been some reports on the preparation of magnetic particles coated with mesoporous shells. Magnetic core/mesoporous silica shell structures were synthesized by sol-gel reaction on hematite particles followed by $\mathrm{H}_{2}$ reduction [16,17]. The magnetic nanocrystals and $\mathrm{GdSe} / \mathrm{ZnS}$ quantum dots were embedded in mesoporous silica spheres by sol-gel reaction [18]. In these reports, hematite particles and magnetic nanocrystals were firstly synthesized, and then were coated with mesoporous silica shell. It can be seen that these procedures required very strict control over the synthesis conditions and the yield is relatively low. Fuertes and co-workers [19] recently reported an incipient wetness impregnation technique to synthesize carbon capsules with a variety of inorganic materials. This method is attractive. However the inorganic solution has to be added dropwise until incipient wetness, and the procedure should be repeated many times for desired loading amount. Herein, we use a new route to fabricate hollow mesoporous silica with magnetite cores (HMSMC) and the amount of magnetite cores can be easily adjusted by changing the concentration of iron nitrate solution used in the synthesis procedure.

The strategy for the synthesis of the magnetic cores embedded in HMS is designed and presented in Fig. 1. First, the

State Key Laboratory of High Performance and Superfine Microstructure, Shanghai Institute of Ceramics, Chinese Academy of Science, Shanghai 200050, People's Republic of China

*Corresponding author. Tel.: +86-21-52412714, Fax: +86-21-52413122, Email: jlshi@sunm.shcnc.ac.cn 


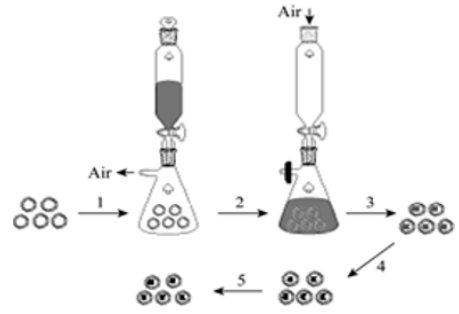

FIG. 1. Illustration of the synthesis procedure of HMSMC composites: (1) adding HMS into iron nitrate solution and vacuumizing; (2) pump switched off and air filled in; (3) sample separation from the suspension; (4) calcination; (5) reduction.

uniform hollow mesoporous spheres (HMS) were obtained via the way reported by $\operatorname{Tan}^{5}$ (TEM images of as-synthesized HMSs are shown in Electronic Supplementary Materials (ESM) Fig. 1). A certain amount of dewatered HMSs was vacuumized for a few minutes, and then the vacuum pump was turned off, and the ethanol iron nitrate solution $(0.25,0.5$ or $1.0 \mathrm{M})$ and air was let to be filled into the system till normal air atmosphere. So the HMSs were immersed in solution. After a few minutes, the iron nitrate solution was removed and the precipitate was dried at $333 \mathrm{~K}$. The resulting powder was washed twice by ethanol, and dried again. After that, the powder was calcined at $773 \mathrm{~K}$ for 2 $\mathrm{h}$ to yield the hollow mesoporous silica spheres with hematite cores (HMSHC). The reduction was carried out by the thermal treatment of the HMSHC particles in mixed $\mathrm{H}_{2}(5 \%$ volume percentage) and $\operatorname{Ar}(95 \%$ volume percentage) gases at $683 \mathrm{~K}$ for $5 \mathrm{~h}$, and the final HMSMCs were obtained.

Powder XRD patterns were recorded on a Rigaku D/Max-2550V diffractometer using $\mathrm{Cu} \mathrm{K} \alpha$ radiation $(40 \mathrm{kV}$ and $40 \mathrm{~mA}$ ). The scanning rate was $6 \% \mathrm{~min}$. Nitrogen sorption isotherms at $77 \mathrm{~K}$ were measured on a Micrometitics Tristar 3000 system. Before measurement, samples were pre-treated at $373 \mathrm{~K}$ for $12 \mathrm{~h}$ under nitrogen. The specific surface area and the pore size distribution were calculated from the BET and Barrett-Joyner-Halenda (BJH) data, respectively. TEM images were obtained on a JEM-2010 electron microscope operated at 200 kV. A vibrating-sample magnetometer (PPMS Model 6000 Quantum Design) was used to study the magnetic properties.

The TEM images of HMSHCs (Fig. 2a (0.25M-HMSHC), b (0.5M-HMSHC), c (1.0M-HMSHC), here $0.25,0.5$ and $1.0 \mathrm{M}$ represent the concentrations of iron nitrate solution) show that the hematite are loaded into the hollow cores of HMSs, and the loading amount of hematite increases with the increase of the iron nitrate concentration used in the synthesis. HMSs were also immersed in $0.5 \mathrm{M}$ iron nitrate solution under normal atmosphere for $24 \mathrm{~h}$ as a reference for comparison, which was named as C-HMS. The TEM image of C-HMS (ESM Fig. 2) shows the HMSs have no hematite cores. In the XRD pattern of

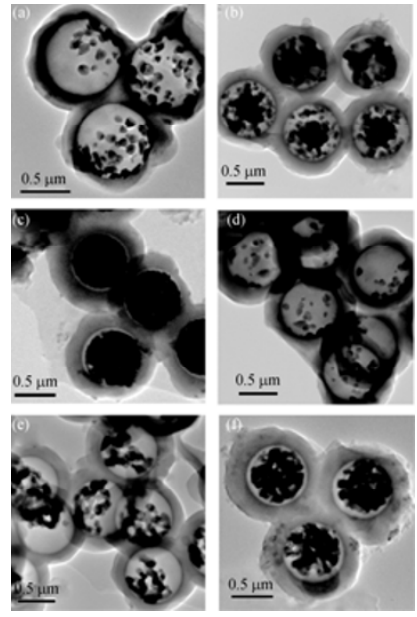

FIG. 2. TEM images of samples $\operatorname{HMSHC}(a, b$, and $c)$ before reduction and $\operatorname{HMSMC}(\mathrm{d}, \mathrm{e}$, and $\mathrm{f}$ ) after reduction prepared by using iron nitrate solutions of different concentrations of $0.25 \mathrm{M}(\mathrm{a}, \mathrm{d}), 0.5 \mathrm{M}(\mathrm{b}, \mathrm{e})$ and $1.0 \mathrm{M}(\mathrm{c}, \mathrm{f})$.

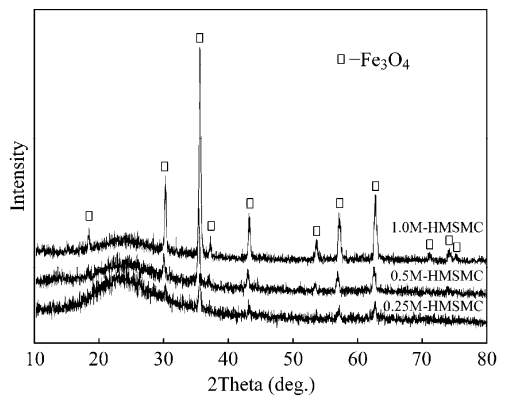

FIG. 3. XRD pattern of HMSMC composites prepared using iron nitrate solutions of different concentrations.

HMSHCs (ESM Fig. 3), all the diffraction peaks match well with the standard PDF data (JCPDS NOS. 33-0664) of hematite, confirming the formation of $\alpha-\mathrm{Fe}_{2} \mathrm{O}_{3}$ and the peak intensity increases with the increase of the iron nitrate concentration used in the synthesis of HMSHCs, which also depicts that the loading amount of hematite cores can be adjusted by changing the concentration of iron nitrate solutions. Comparatively, the XRD pattern of C-HMS gives no apparent diffraction peaks, in accordance with the TEM results. The TEM images of the reduced HMSMCs (Fig. 2d (0.25M-HMSMC), e (0.5MHMSMC) and $\mathrm{f}(1.0 \mathrm{M}-\mathrm{HMSMC})$ ) show that the cores have shrunk and the amount of magnetic cores increases with the increase of hematite amount loaded. In the XRD pattern of Fig. 3 , all diffraction peaks matching well with the standard PDF data (JCPDS No. 19-0629) confirm that the reduced cores are single-phase of magnetite $\mathrm{Fe}_{3} \mathrm{O}_{4}$. The reduction products can be controlled, according to the typical reduction process of hematite: $\alpha-\mathrm{Fe}_{2} \mathrm{O}_{3} \rightarrow \mathrm{Fe}_{3} \mathrm{O}_{4} \rightarrow \mathrm{FeO} \rightarrow \mathrm{Fe}$, by altering the reduction temperature or time $[16,20]$. The diffraction intensities of different samples increase in accordance with the increase of the loading amount of magnetic particles in the hollow cores. So we can easily control the loading amount of hematite and 
magnetic cores by adjusting the iron nitrate concentration in the synthesis of HMSMCs.

The magnetization curves of the HMSMCs at room temperature (Fig. 4) shows magnetic hysteresis loops, which demonstrates the magnetic response to a varying magnetic field. The saturation magnetization values of HMSMCs are 2.2, 7.2 and $22.0 \mathrm{emu} / \mathrm{g}$ for $0.25 \mathrm{M}-, 0.5 \mathrm{M}-$ and 1.0M-HMSMC, respectively. The coercivity values are approximately 250 Oe for $0.25 \mathrm{M}-, 0.5 \mathrm{M}-$ and $1.0 \mathrm{M}-\mathrm{HMSMC}$, as estimated from the inset of Fig. 4.

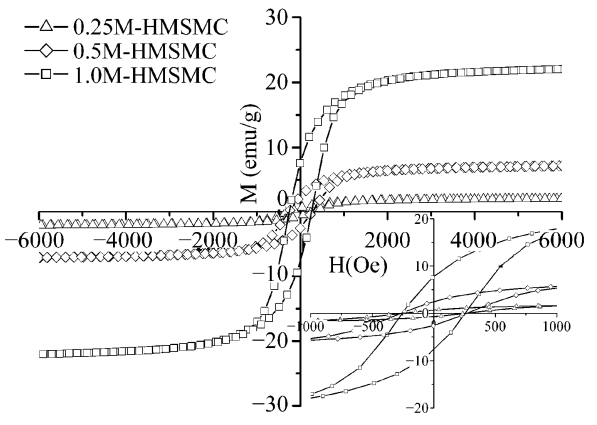

FIG. 4. Magnetic properties of HMSMC at room temperature.

The $\mathrm{N}_{2}$ adsorption/desorption isotherms were recorded to investigate the pore properties of as-prepared HMS, 0.25M-, 0.5M- and 1.0M-HMSMC (ESM Fig. 4). All isotherms show the characteristic of mesoporous materials: type-IV isotherms with a marked leap in the adsorption branch at relative pressures $\mathrm{P} / \mathrm{P}_{0}$ between 0.2 and 0.4 . This indicates that the mesostructure of HMSs has been kept after loading the magnetite cores. The structure parameters of all samples are summarized in Table 1. Here, similar pore size distributions for all samples, around $2.4 \mathrm{~nm}$, can be found in Table 1. And the surface area is found to decrease gradually from HMSs, 0.25M-HMSMC, 0.5M- HMSMC to 1.0M-HMASMC, and the pore volume also decreases in the same order. The main reason for such decreases can be attributed to the presence of magnetite cores, which have higher density than silica.

In conclusion, we have successfully fabricated hollow mesoporous silica spheres with magnetite cores by a vacuum nano-casting route. The loading amount of the magnetite cores and saturation magnetization values of HMSMC can be adjusted by simply changing the concentration of iron nitrate solution used in the synthesis procedure. Relatively high surface area $\left(149 \mathrm{~m}^{2} / \mathrm{g}\right)$, large pore volume $\left(0.19 \mathrm{~cm}^{3} / \mathrm{g}\right)$, and mesoporous shell can be obtained for the HMSMC which has a saturation magnetization value of $22.0 \mathrm{emu} / \mathrm{g}$.

We gratefully acknowledge the support of this research by the National Science Foundation of China (Grant No.50702072),
Chinese Academy of Science (Grant No.KJCX2.YW.M02), National 863 Projects (Grant No.2007AA03Z317) and Shanghai Nano - Science Program (Grant No.0852nm03900).

Received 20 October 2009; accepted 30 October 2009; published online 15 November 2009.

\section{References}

1. G. Zhu, S. Qiu, O. Terasaki and Y. Wei, J. Am. Chem. Soc. 123, 7723 (2001). doi:10.1021/ja0158758

2. S. B. Yoon, K. Sohn, J. Y. Kim, C. H. Shin, J. S. Yu and T. Hyeon, Adv. Mater. 14, 19 (2002).

3. Y. S. Li, J. L. Shi, Z. L. Hua, H. R. Chen, M. L. Ruan and D. S. Yan, Nano. Lett. 3, 609 (2003).

4. Y. F. Zhu, J. L. Shi, H. R. Chen, W. H. Shen, X. P. Dong and Micropor. Mesopor. Mater. 84, 218 (2005).

5. B. Tan and S. E. Rankin, Langmuir 218180 (2005).

6. H. Djojoputro, X. F. Zhou, S. Z. Qiao, L. Z. Wang, C. Z. Yu and G. Q. Lu, J. Am. Chem. Soc. 128, 6320 (2006).

7. F. J. Suárez, M. Sevilla, S. Álvarez, T. Valdés-Solís and A. B. Fuertes, Chem. Mater. 19, 3096 (2007).

8. L. M. Guo, X. P. Dong, X. Z. Cui, F. M. Cui and J. L. Shi, Mater. Lett. 63, 1141 (2009). doi:10.1021/n1034134x

9. A. H. Lu, W. C. Li, A. Kiefer, W. Schmidt, E. Bill, G. Fink and F. Schüth, J. Am. Chem. Soc. 126, 8616 (2004).

10. S. Giri, B. G. Trewyn, M. P. Stellmaker and V. S. Y. Lin, Angew. Chem. Int. Ed. 44, 5038 (2005).

11. A. B. Fuertes and P. Tartaj, Chem. Mater. 18, 1675 (2006).

12. A. B. Fuertes and P. Tartaj, Small 3, 275 (2007).

13. X. P. Dong, H. R. Chen, W. R. Zhao, X. Li and J. L. Shi, Chem. Mater. 19, 3484 (2007). doi:10.1021/cm0709065

14. N. Andersson, R. W. Corkery and P. C. A. Alberius, J. Mater. Chem. 17, 2700 (2007). doi:10.1039/b618502a

15. L. M. Guo, J. T. Li, L. X. Zhang, J. B. Li, Y. S. Li, C. C. Yu, J. L. Shi, M. L. Ruan and J. W. Feng, J. Mater. Chem. 18, 2733 (2008). doi:10.1039/b802857e

16. W. R. Zhao, J. L. Gu, L. X. Zhang, H. R. Chen and J. L. Shi, J. Am. Chem. Soc. 127, 8916 (2005).

17. D. K. Yi, S. S. Lee, G. C. Papaefthymiou and J. Y. Ying, Chem. Mater. 18, 614 (2006). doi:10.1021/cm0512979

18. J. Kim, J. E. Lee, J. Lee, J. H. Yu, B. C. Kim, K. An, Y. Hwang, C. H. Shin, J. G. Park, J. Kim and T. Hyeon, J. Am. Chem. Soc. 128, 688 (2006). doi:10.1021/ja0565875

19. A. B. Fuertes, M. Sevilla, T. Valdes-Solis and P Tartaj, Chem. Mater. 19, 5418 (2007). doi:10.1021/cm071713k

20. M. Ohmori, E. Matijevic and J. Colloid. Interface. Sci. 160, 288 (1993). doi:10.1006/jcis.1993.1398 